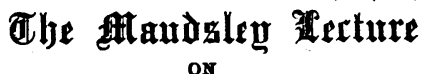

\section{THE PREVENTION OF INSANITY.} BY

Professon GEORGE M. ROBERTSON, PRESIDENT OF THE ROYAL COLLEGE OF PHYSICIANS, EDINBURGH.

\section{(Abstract.)}

Professor Robertson divided his subject into two parts: first, the influences which go to the causation of insanity secondly, observations on the theories and methods of prevention, particularly of general paralysis of the insane. The statistics he used were taken from the twenty-first annual report of the Commission in Lunacy of the Stato of New York for the year 1908-09.

\section{Conditions and Influences Affecting the Occurrence of Insanity.}

From these statistics it appeared that insanity under the age of 15 was quite negligible and if included in statistics of insanity had a most disturbing effect, as this period of life comprised nearly a third of the population. A high birth rate and a low infantile mortality would increase the population at this period, and the effect of this proportionate increase would be to reduce the apparent amount of insanity in the total population, without any real diminution of insanity. A fair number of admissions occurred between 15 and 19 , and a larger number between 20 and 24. The amount continued very high up to 40 years of age, after which it fell, so that it appeared that the early years of life were the most liable to insanity, and with increasing years a mental breakdown became every year moro remote. But these statistics did not represent the rate of incidence of the liability to insanity-that is to say, the froquency with which insanity occurred in proportion to the number living. The large number of admissions recorded between 20 and 40 was mainly due to the large number of persons living in early life, and the small number of admissions at 75 resulted from the small number alive in old age. Statistics of incidence showed that insanity tended to develop between 15 and 19, but became nuch more pronounced between 20 and 24 . This was followed by a steady rise vear after vear till the age of 50 was reached. There was then a short period of decline, after which there was an extremely rapid rise in old age. There was a general tendency for insanity to become more frequent as one grew older. To emphasize the difference between the number of admissions at the various age periods and the rate of incidence of insanity at these periods Professor Robertson brought the two charts together for the purpose of comparison.

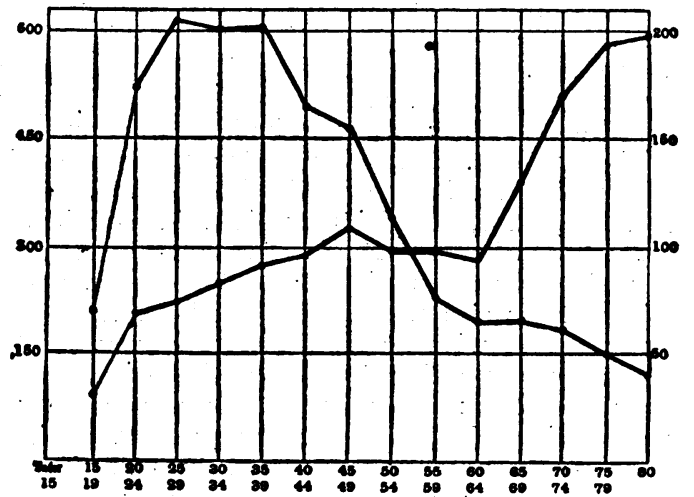

FiG. 1.-Graph of total number of first arimissions $(5,222)$ compared with rate of incidence of insanity per 100,000 of the population at with rate of incidence of insanity per 100

Incidence of Insanity among Males and Females.

As regards sex, insanity occurred among males at a proportionately higher rate than among females. This unexpected result was mainly due to the greater number of admissions from general paralysis and alcoholic insanity. * Delivered before the Royal Medico-Psychological Association on July 15th.
Among the married the incidence of insanity was decidedly low. It was slightly higher among women under 35 than among men, and this was no doubt connected with tho risks of child-bearing. The less of a husband or a wife increased in a marked manner the incidence of insanity. Up to the age of 55 the prevalence of insanity among widows and widowers was almost double that among married men and women. The symptoms of insanity in these people were to a large extent a wrong method of adjustment to difficulties in life, and the increased amount of insanity among widows and widowers was both a sociological and a biological phenomenon. Between the ages of 25 and 55 the prevalence of insanity among single men and women was nearly three times as great as among a similar number of married men and women of the same age. The causes of this high prevalence among the single were involved; but the average health of the single was probably lower than that of the married, for ill health might be itself a reason for remaining single. Professor Robertson concluded, from the low incidence of insanity among the married, that the condition of marriage and of family life, in spite of its greater responsibilities, perhaps on account of them, was the most favourable mode of existenco for men and women. Young men between 25 and 35 years of age continuing bachelors died on the average four years sooner than married men, and ran three times the risk of becoming insane.

The Three Critical Periods of Life.

Coming to the three critical periods of life, all connected in some measure with the function of sex, Professor Robertson remarked that during pubescence and adolescence the balance of the internal secretions of the body was disturbed by the intrusion of the internal secretion from the sexual glands. For all practical purposes insanity occurred for the first time at this period of life. Leaving on one side the effect of heredity, there was in insanity almost always a physical cause, but usually combined with mental causes. The physical cause in adolescent insanity was the physiological disturbance produced by the internal secretions. The mental cause was the change in the social status of the young adult or adolescent. He had to adjust himself to the problems of life, and of these the most disturbing during these early years were those connected with sex.

The next critical period was the climacteric, occurring between 45 and 50 . This was the age when, the powers first began to fail; an age when to keej abreast of younger competitors increased effort was needed. When the climacteric had been surmounted, the incidence of insanity for a period fell steadily. This period, accompanied by a damping down of the fires of emotion, was one of the most valuable. The mind had become stabilized. Wisdom had increased with experience of life. Men of this age guided the destinies of mankind. The third crisis, said Professor Robertson, was known as the grand climacteric, when the period of senescence began. After the age of 64 the rate of incidence of insanity mounted year by year with extreme rapidity, and was proportionately almost double that of the period of adolescence. Above 75 it was almost treble. The incidence was more marked even than was recognized, since many senile persons were cared for at home and were never registered as insane. The crisis of the grand climacteric supported the regulation of the Civil Service that 64 was the age for retirement.

Hereditary, Acquired, and Senile Insanity.

Professor Robertson then divided insanity into three distinctive types-the hereditary, the acquired, and the decadent, associated with three age periods - early adult life, middle age, and senescence, although not limited to them.

He said that the number of admissions of dementia praecox was large, that it was malignant in character, that only 15 per cent. of those afflicted with it recovered, so that the majority of the patients became permanent residents and filled mental hospitals. This gave the impression that the early period of life was the most liable to insanity, whereas adolescence was actually the least dangerous period of life for insanity in general. If, however, we refer to the hereditary insanities alone, and 
especially if we restrict our attention to the most malignant type of insanity, dementia praecox, then adolescence is undoubtedly a dangerous period of Iife. As the individual grew older the danger of a breakdown from dementia praecox-grew less. Between 40 and 45 it was exactly half of what it was between 20 and 25 .

Manic-depressive insanity, the other important form of hereditary insanity, was not so prevalent in early adult life as dementia praecox, but its hereditary character was displayed by its tendency to recur. It was the benign type of hereditary insanity, and the vast majority of patients suffering from it, who were in good bodily health, made excellent recoveries. Manic-depressive insanity, being a disorder of the emotions, was more frequent among females than among males. The disease in males might be wrongly diagnosed as alcoholic insanity because the patients had taken to drink. In the elated phase of the disorder the patient drank because of his high spirits, and in the depressive phase in order to drown his sorrow.

The two most important forms of insanity in middle life were alcoholic insanity and general paralysis of the insane, and both occurred more frequently in men than in women. Both of them were acquired forms of insanity, and there fore preventable. The diagnosis of alcoholic insanity was uncertain, and depended largely on the personal equation of the observer. The part played by heredity created uncertainty in every case. To suffer from alcoholic insanity one must first be alcoholizable by hereditary predisposition. Alcohol, according to Féré, was th "touchstone of mental equilibrium," and to be able to resist the toxic effects of alcohol betokened a well controlled mind and a sound brain. Mercier had pointed out that there were always two factors in the production of insanity-an internal and an external. The internal factor represented the hereditary tendency; the external, some exciting cause in the environment. These factors were always inversely proportional. If the intermal factor or hereditary tendency to insanity was strong, then the external or alcoholic factor was weak; but if the hereditary predisposition to insanity was slight, then the exciting cause must be strong. The graph of alcoholic insanity in

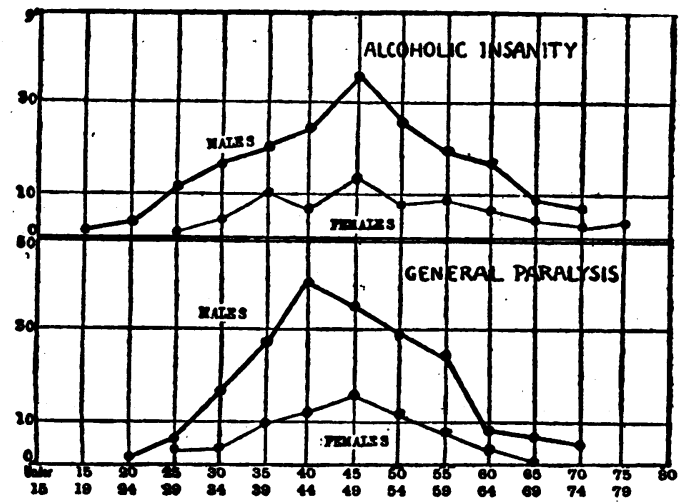

Fig. 2.-Alcoholic insanity and general paralysis. Male and female admissions separately per 100,000 of the population.

males was as perfect as the outline of Fujiyama. The sharp apex of the cone seemed to indicate that there was in the male a climacteric which corresponded to the female menopause.

The incidence of general paralysis of the insane in both sexes resembled that of alcoholic insanity. It reached its period of maximum incidence five years earlier than was the case with alcoholic insanity. Its onset was probably determined by the date of infection by syphilis. We are now in possession of two promising forms of treatment -namely, benign tertian malaria and tryparsamide. In early cases after malarial treatment about a third of the patients were able to return to work, and another third were distinctly improved. Apparent recoveries had also been effected by tryparsamide alone, which was by far the most potent arsenical preparation for the treatment of this disease.

The mental decay of old age would come, said Professor Robertson, to every human being if he lived long enough; but no physiological process showed more extreme varia tions than the time of onset of senectitude. Senile insanity was closely related to the waning of the bodily functions and to those diseases to which the anged are liable. Dr. John Carswell had made some interesting observations on the relation between the death rate and the occurrence of insanity. He selected ten wards in the city of Glasgow with a combined population of nearly 400,000 , and divided them into two practically equal groups, the one with a death rate below, and the other with a death rate above, that of the whole city, called for convenience the healthy and the unhealthy groups. He also subdivided each group into two sections, the one consisting of persons between 15 and 44, and the other of those above 45 years of age-in other words, a younger and an older section. Dealing first with the younger sections, and making use of first attacks only, Dr. Carswell found that in three years there were 165 cases of insanity in the healthy group and 186 in the unhealthy group. This difference was slight, so he concluded that health of body was probably not the main factor in the production of insanity in the early period of life; 67 per cent. of tho cases were due to constitutional or hereditary influences. Dealing next with the older sections he found in the unhealthy group 149 cases of insanity, as compared with only 91 in the healthy group-an increase of 61 per cent. He therefore concluded that ill health of body was an important factor in the production of insanity, being léss in a district in which comfort was enjoyed and the death rate was low. Improved social conditions did not apparently lead to any marked diminution in the amount of insanity during early adult life, as the forms of insanity were then mainly hereditary. They apparently reduced the amount of senile insanity.

The preventive aspect of his survey, said Professor Robertson, fell naturally into a consideration of the measures to be taken to deal with the three types of insanity-the hereditary, the acquired, and the senile.

Prevention of the Hereditary Insanities: Eugenics.

It was sometimes alleged, on the original authority of Morel, that when insanity made its appearance in a stock it arose at an earlier age and in a more severe form in every subsequent generation, so that in the third or fourth generation it was represented by imbecility and idiocy, and the stock came to an end. This progressive degeneration was described by Sir Thomas Clouston as Nature's method of killing off a bad stock. There were errors as well as false suggestions in these statements. When insanity first made its appearance in a stock there was no necessity for it to continue, far less to arise in an earlier and more severe form in each successive generation. If bad stock married into bad, the offspring was naturally less fit than either parent, and if this policy were continued for two or three generations the family ultimately came to an end. But, just as insanity might appear in a family previously sound, owing to unfortunate mating, so it might also disappear, when it had once occurred, owing to propitious unions. Maudsley wrote: "The two principal modes by which an insane strain in a family is worked out of it are, first, propitious unions in marriage, with sound stocks, whereby it is attenuated, neutralized, perhaps ultimately extinguished; and, secondly, propitious dispositions of the circumstances of life." Of these methods he remarked that without doubt the first was most effective. In a process allied to progressive degeneration to which Sir Frederick Mott had given the name "antedating or anticipation," an hereditary form of insanity, usually dementia praecox, appeared in offspring at an earlier age than an attack of insanity in the parent. These precocious attacks of malignant insanity Professor Robertson believed to be the result of unpropitious unions. They indicated that the hereditary tendency in the offspring was greater than it was in either parent. It was clearly a social duty on the part of those inheriting a neuropathic strain to avoid marriage into stocks with a similar: weakness, if offspring were expected. In the case of those with obvious mental defect or subject to a severe psychosis marriage should not be contemplated. Belief in the evil effects of the marriage of cousins had ounk deep into the 
popular mind, but in itself consanguinity did no harm, provided the stock was good. As for the question of sterilization, Professor Robertson was not convinced by the theoretical arguments in its favour. He believed the bulk of the medical profession regarded the proposal as such an outrage on their traditional ideals of duty towards their patients that its adoption was impracticable in this country. He could not imagine a board of physicians calmly sentencing a victim to this cold-blooded and superfluous insult. Enthusiasm had overstepped the bounds of reason when a writer declared that " if sterilization should be permanently prohibited, it will be impossible to prevent a slow but steady deterioration of all such civilized races as are so strongly endowed with human sentiments as to prevent infanticide from becoming a permissible practice."

In support of his views on this subject and to show how little the extent of mental disease was appreciated, Professor Robertson quoted an inquiry by Sir Thomas Clouston, who found that in three generations in 41 of 83 families with which he was acquainted in a country parish in Scotland one or other of four diseases had occurrednamely, mental disease, congenital imbecility, idiocy, or epilepsy. Sir Thomas Clouston had no doubt that if his information had been quite perfect, a few more families would have been found to have produced those diseases. The lesson of this study in heredity showed how much room there was for the practice of mental hygiene, of moral control, of abstinence from deteriorating agents, of cultivating good health, and of arranging marriages on right principles, to counteract, and in time perhaps to eradicate, those morbid nervous and mental tendencies.

\section{Mental Hygiene of Childhood and Adolescence.}

To eradicate "morbid nervous and mental tendencies," Professor Robertson continued, is the avowed aim of eugenics, and stripped of excrescences eugenics might one day help to lay the foundations of a healthier and a more efficient race. That goal achieved, it must still be remembered that the task of producing healthy-minded men and women does not end. Every human being is a living and developing organism, bound by his nature to react to the influences of his environment, especially so if they were brought to bear on him during the most plastic phase of life. Even the defective child showed the influence of discerning management and an environment adapted to its responsive capacity, a consideration which went far to justify the large expenditure of public funds in the provision of special institutions and schools for this class. But the advantages so laboriously acquired were squandered by making indifferent provision for lifelong care, and the rectification of this failure was one of tho necessities of our time. There was also need for the earliest possible recognition of mental defect, and for a closer study of the ante-natal as distinguished from the hereditary conditions of defect.

In Professor Robertson's opinion the mind of man was not born-it was made. At the outset all those forces which left their imprint on the child were combined in the personality of the mother, and practical hygienic measures must be concentrated on her rather than on the child. The subsequent development of the child involved the transition from the state of dependence to comparative freedom. The social instincts had to be developed through contact with the other members of the family, and later with the community at large. Home influences had subsequently to be tempered by the discipline of school life. Through such experiences the primitive, self-seeking tendencies were subordinated to the higher self, and their Iatent energy set free for the achievement of social ends. Tho danger inherent in this long travail was lest in the end the primary instinctive tendencies should triumph over the educative influences. Out of the failure to master the temptations was born the type of temperament in which the seeds of dementia praecox and other forms of mental disorder found a congenial soil. Without doubt, the mental hygiene of childhood and of adolescence played a most important part in the prevention of insanity.

Professor Robertson applied the term "prophylaxis" to particular steps taken with the immediate object of pro- tecting the mind when threatened by danger. It was essential, for example, to those with a known hereditary predisposition who had already suffered from an attack, and especially to those in whom the attack had been of a recurrent type, such as manic-depressive insanity. When such a case occurred it should be borne in mind that the other members of the family inherited a similar predisposition. The warning indications were, first, loss of sleep. Extreme or prolonged insomnia was a danger, and precautions should be taken. Secondly, there was prolonged anxiety that could not be dislodged. Another danger signal was mental and physical exhaustion. A change of character, not amounting to actual insanity, was another important sign, particularly in those who were subject to manic-depressive insanity. Sometimes the patient was morbidly elated, at others he was morbidly depressed. These changes of mood could bo controlled only to a limited extent, but much could be done to prevent their exaggeration into something definitely morbid.

\section{Early Treatment.}

It was believed by many that some of the cases receiving treatment for the prevention of insanity would not develop insanity were they to receive none. Such authorities believed that these cases of the psycho-neuroses, which others regarded as exhibiting the early stage of insanity, suffered really from a definite type of mental disorder of a different kind. It was even alleged by them that the presence of a psycho-neurosis was a protection against insanity. Professor Robertson was inclined to agree that once a psycho-neurosis had assumed a definite form, although it varied from time to time in its severity and in the details of its symptomatology, it did not tend to alter its character, or to assume that of insanity, any more than one definite form of fully developed insanity tended to alter into another. To this extent the treatment of the psychoneuroses was not the early treatment of insanity, nor could such treatment claim to prevent insanity from developing where that danger did not exist. To this extent also the existence of a definite type of psycho-neurosis, except in rare instances, might be said to protect the individual from the occurrence of actual insanity. But at an early stage it was impossible to foretell whether transient, vague, and disorderly mental phenomena would develop into a typical psycho-neurosis or into a definite form of insanity. There were two stages-an initial stage when anything was possible, and a later stage when the type was fixed.

\section{Prevention of the Acquired Insanities.}

In the middle period of life the benefits of prevention were more noticeable because they were more immediate. Insanity at this period was largely acquired, and could of ten be prevented. Myxoedematous insanity, for example, had diminished almost to the vanishing point since the discovery of its cause was made. Just as heredity was a factor to be reckoned with to a greater or less extent in every case of insanity, so we were beginning to recognize that disturbance of the internal secretions played a more or less important part in all forms of mental disorder. Any future great therapeutic discovery in the domain of mental disease would probably be found in a knowledge and control of the internal secretions.

Professor Robertson then said that as regards the prevention or abolition of alcoholic insanity there is a very simple way of effecting this, provided it is voluntary. But even if alcohol were prohibited, not in the legal but in the real sense, the total number of cases of insanity would not be diminished by the full number of cases diagnosed as alcoholic insanity. Many of these, owing to inherent instability, would break down from other causes in the absence of alcohol. On the other hand, alcohol is a contributing factor but not the principal cause of insanity in many other cases, and in these abstinence might be the means of averting insanity altogether. Alcoholic insanity is diminishing, though not so rapidly as most people desire. The habit of drinking is on the decline, and it is no small boon that drunkenness is on the decrease and in some places has entirely disappeared.

The other important form of acquired insanity is general paralysis. An astounding fall in the number of deaths was 
recorded in 1919, and this has continued, and is of supreme interest from the point of view of prevention. From 1907 to 1918 inclusive the number of male deaths was steady, and for eight years the biennial numbers did not vary more than 10. In 1918-20 there was a sudden drop of 26 per cent. The following appears to be the probable explanation of this sudden fall in the number of deaths. General paralysis may appear within three years after syphilis has been contracted, but it is not till seven years have elapsed that it occurs with any frequency. Of those attacked more than a half die within two years after the first appearance of the symptoms, which are usually present for a year before the patient is admitted to a mental hospital. If, therefore, persons develop general paralysis seven year's after infection, and if a half die within two years, we require to go back nine years to find an explanation for any variation in the death rate. In other words, to explain a sudden fall in the number of deaths in 1919 we require to investigate conditions in 1910. If this be done an explanation is found in the employment during that year of salvarsan and the cure by its use of those males who contracted syphilis. As the fall in the number of deaths in 1919-20 is 26 per cent., it is certain that many who had contracted syphilis previous to 1910 and 1911 also took advantage of the discovery of the new remedy.

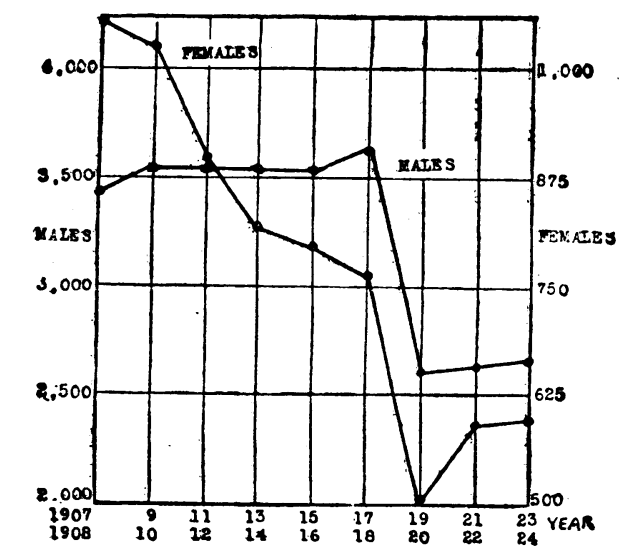

Fig. 3.-Numbers of deaths from general paralysis in England and
Walcs in biennial periods from 1907 to 1924 , males siparately. Graph of females four times enlarged as compared with graph of males.

The above chart has been designed from the number given to illustrate the deaths in biennial periods, and as the proportion of deaths of males to females is about 4 to 1 the graph for females has been enlarged four times to make its variations comparable. The graph for females is remarkable. There is a steady fall from 1907 to 1918 , which amounted in that year to 28 per cent. Great as this reduction is, it cannot be attributed to the treatment women received, as comparatively little wa; done for them till venereal clinics were established in 1920. The explanation of this fail is believed to be as follows: Syphilis is infectious, and in dealing with 111fectious diseases the treatment of the individual case is of ?ess importance than the prevention of the spread of infection. During the first decade of the century treatment by mercurial inunction was employed, and this form of treatment was a long one. The opportunity was takin of instructing male patients regarding the nature of the aisease they were suffering from and of appealing to them to avoid infecting others. Many men, it would seem, acted on this advice, but the result was strangely onesided. In other infectious discases, when precautions against infection are taken, benefit is received by all alike. Syphilis, however, is peculiar, as it spreads from one sex to the other, and if one sex only adopts measures to avoid spreading infection the whole benefit of these precautions is received by persons of the opposite sex alone. It is thus that we account for the continuous fall of femain deaths from general paralysis from 1907 to 1918, whtle the deaths of males remained stationary, or even tended to rise. There was a further fall of $3 \dot{3}$ per cent. in the number of female deaths from general paralysis in 1919-20, as compared with the two previous years. This corrosponds exactly with the fall in the deaths of males in time and proportion, but it was not directly due to treatment by salvarsan as was the case with males. It may, however, be traced to the employment of a rapid method of curing syphilis, with the result that the infectious stage of the disease in males was cut short by salvarsan, and fewer women became infected.

These observations teach us two lessons. The first, the success of modern scientific methods in preventing the most terrible malady to which man is subject. The money spent on clinics for the treatment of renereal diseases will in a few years be amply repaid. The other lesson is the effect of educational propaganda and publicity. I attribute the whole fall in the number of deaths from general paralysis among females up to the year 1919 to the instruction given to infected males. I believe also that those who have mainly benefited by the knowledge thus inaparted have been the innocent wives of the less educated classes. Among these classes the proportion of women to men suffering from general paralysis is about 1 to every 4, but it may be as high as 1 to every 3 . Among patients of the richer and better educated classes the proportion is very different: at Craig House there has been only one lady admitted suffering from general paralysis during the last twenty-four years, as compared with 73 men.

$$
\text { Prevention of Senile Insanity. }
$$

As to measures for the prevention of insanity during senility, Professor Robertson continued, we are guided by the knowledge that the later in life insanity begins the less important is the factor of hereditary predisposition in its causation; and that, in all forms of insanity occurring during senility, the influence of the body, if not paranount, predominates. For the prevention of insanity during senility we must begin to interest ourselves in bodily liggiene at a much earlier period. The diseases of old age are usually insidious in origin and gradual in development, and their seeds have been sown in middle life or even earlier. Syphilis and chronic alcoholism, for example, may not lead to auy form of insanity in the early or middle. periods of life, but oning to a progressive degeneration of the blood vessels of the brain and to a general lowering of the vitality, they may induce premature and marked senility and be the essential agents in the causation of insanity late in life. Prevention is then too late. Without doubt preparation for a healthy old age by careful living during the middle period of life is the best insurance against senile insarity. The measures employed to prolong life, by increasing the number of the aged in proportion to the rest of the population, increase the total amount of insanity, for senility is the insanity-producing period of life. If this be associated with later marriage, a falling birth rate, and emigration of the young and fit, so that there is a proportionate diminution of the non-insanity-producing period of life, then in spite of all the efforts of mental and physical hygiene-indeed, partly on account of these efforts - the amount of insanity in proportion to the total population must show a marked increase. These statistical fallacies have to be eliminated before the relative amounts of insanity from year to year, or in different areas, can bo compared with accuracy. The alarmist, naturally, does not trouble to do this.

\section{Is Insanity on the Increase?}

Professor Robertson then turned to the question, Is insanity on the increase? After pointing out that all nations seem to pass through periodic phases in which fears arise that among them the occurrence of insanity is on the increase, he said that so far as can be judged the outlook in this country at the present time is distinctly farourable. In Scotland the total number of insane persons has fallen from 390 per 100,000 in the first quinquennium of the last fifteen years to 369 in the last; and the number of insane persons registered annually for the first time has fallen from 2,828 in the first quinquennium to 2,731 in the last, although the population has increased in number. 
Conclusion.

In conclusion, said Professor Robertson, it must be apparent to everyone that the problem of preventing mental disorder is not a simple one. The analogous problem is that of the prevention of tuberculosis, with which it has so many points in common, and from the campaign for its prevention much can be learned. The possible causes of mental derangement are legion, and the possible combination of these, in individual cases, beyond counting. It is clear that when sickness of mind threatens or occurs, mental health cannot be regained by any royal road. The claims of the individual sufferer are in the first place paramount and must be studied. Every case of threatened breakdown presents a unique problem. It may have features in common with others; it certainly will present features peculiar to itself. Intensive study, therefore, of individual cases, so as to disclose these causative factors, is the primary duty of the psychiatrist. If that duty be not discharged, treatment will be confined to a few rule-of-thumb precepts, and its results will be disappointing. Secondly, what ean be done in a more general way is well illustrated in the case of general paralysis. By disseminating, as widely as possible, information as to its mode of attack and the methods of prevention, a real contribution has been made to the mental hrgiene of the community. Encouraged by that success, let us see to it that our knowledge of the origin and development of other disabling conditions is effectively applied wherever it is needed. In the opening up of these preventive channels a great responsibility rests on practising psychiatrists. It is futile to lament that those of unstable equilibrium turn elsewhere for help-to the quack, to the charlatan, to the barren ritual of the latest cult. The blame for this state of affairs must be shared by the psychiatrist. Far too long has he sulked in his cave; now he must come out into the market-place and offer his wares to all who need them. He must not confine his interests to his duties in the mental hospital. He must co-operate with the general practitioner and get into touch with the outer world through the agency of out-patient clinics. An expert body of psychiatrists, trained in every derice of medicine and psychology, and diligently applying themselves to the clamant needs of their generation, might avert much needless suffering on the part of those in mental difficulties or about to be overwhelmed. Let none be daunted by the magnitude of the enterprise that is envisaged, but rather find in it an incentive to continued and combined effort, and the hope of a greater reward.

\section{DARK-GROUND HLUMINATION OF TISSUE CELLS CULTIVATED “IN VITRO.”}

BY

T. S. P. STRANGEWAYS, M.A., M.R.C.S., L.R.C.P. LECTURER in special patfrology, CaMbridGe university; DIRECTOR, GAMBRIDGE RESEARCH HOSPITAL.

AND

R. G. CANTI, M.D.

LECTURGR IY BACTERTOLOGY, ST. BARTHOLOMEW'S HOSPITAL, LONDON.

(From the Laboratories of the Research Hospital, Cambridge.)

THE cultivation of animal tissues in vitro is now a recognized method of research. When a fragment of tissue is cultirated upon a cover-slip in suitable medium a zone of cells grows out around the edge of the fragment. Many of these cells become adherent to the surface of the coverslip and wander over it by amoeboid movement, pushing their war along the plane between the glass and plasma jelly. Such cells are very suitable for microseopieal observation, and studies of the cells carried out under direct illumination have alread'y been reported. ${ }^{1}$ The thin film of groming cells is peculiarly suitable for observation by dark-ground illumination, and by this method beautiful and irrstrnctive pictures of the living vegetative cells can be obtained. The technique for this examination requires considerable experience and care, but presents no great difficulty to workers familiar with critical mieroscopic technique. * A demonstration given to the Section of Pathology and Bacteriology
The following description of the apparatus and methods used for the examination and study of tissue cells by darkground illumination may be useful to workers not familiar with this method of microscopic examination.

The cultures must be put up on thin glass slides not more than $0.6 \mathrm{~mm}$. in thiekness, and the thickness of the whole preparation must not exceed $0.9 \mathrm{~mm}$.

The tissue may be cultivated in plasma or in plasma and cmbryo extract on a cover-slip sealed over a hellow-gronnd slide, and just before examination the cover-slip can te removed and transferred to a thin glass slide on which a drop of Tyrode or other suitable saline solution has been placed; the cover-slip is then sealed down with paraffin wax to prevent evaporation.

A better method, however, is to cultivate the tissues directly on the thin glass slide. By this means it is possible to use cultures growing in fuid as well as semisolid media. Care must be taken not to press upon the cover-slip while handling the cultures as pressure may damage the growing cells. Too violent excursions of the oil-immersion objective will also eause damage.

The microscope we have used is a Zeiss microphotographic stand with mechanical stage and sliding objective carriers. Before any attempt is made to use the dark-ground condenser the objectives must be carefully centred. A triple nosepiece is to be avoided, as the three portions are seldom in exact optical centre and cannot be adjusted. The sliding carriers, on the other hand, are readily adjusted, and with a little experience give no more trouble than a triple nosepiece. Each objective must be centred and kept on its own carrier.

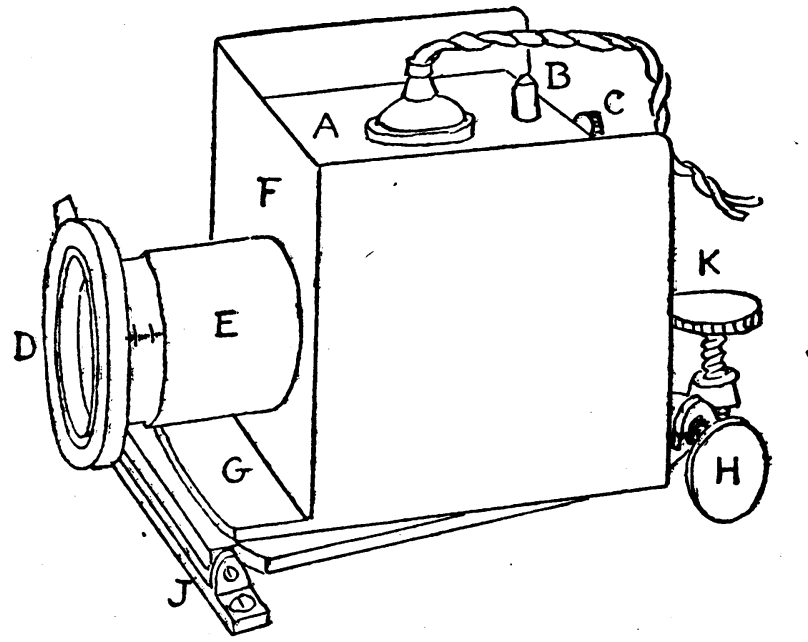

FIG. 1.-Diagrammatic drawing of lantern. A, Metal shield bent at right angles holding a pointolite lomp; the whole sides on B, a stee rod to which it is fixed with a thumbscrew C. This arrangement altows the lamp to be moved as required for eentring with the lens $B$. The lens carrier slides in a sleeve, E, fixed to the front of the Eody of the box steel centre and rides on a similar cast brass plate, movement tatergiry being obtained by the thumbscrew $H$. The bower plate is in turn pivoted at its forward end to a bar, J, fixed to the table, so that the whole lantern can be tilted up or down by the thumbscrew $K$.

The following instructions for centring the objective may be nseful to those not accustomed to critical work.

1. Swing out the lower substage diaphragm, and the Abbé condenser, leaving the upper substage diaphragm in position; close this as far as possible

2. Place the 2/3 inch objective with its sliding carrier in position and, using diffuse light, focus on to the aperture of the diaphragm.

3. Centre the $2 / 3$ inch objective to the aperture of the diaphragm, using the key.

4. Replace the Abbé condenser, and place a centring slide on the microscope stage.

5. Focus on to the cross-line of the centring slide with the $2 / 3$ inch objective and place the cross-line exactly in the centre of the field.

6. Remove the $2 / 3$ inch objective and replace by the $1 / 8$ inch, and later by the $1 / 12$ inch, each on its own carrier. Using the key, centre these lenses to the eross-line.

All the lenses are now centred to the aperture of tho upper substage diaphragm and hence to each other. 